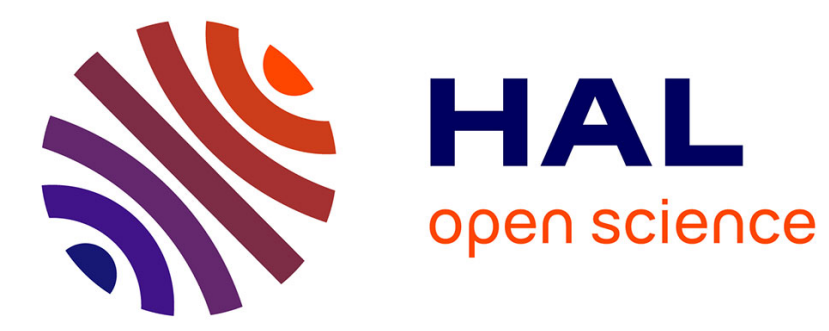

\title{
Contribution of capillary electrophoresis to an integrated vision of humic substances size and charge characterizations
}

\author{
Fanny d'Orlyé, Pascal E. Reiller
}

\section{To cite this version:}

Fanny d'Orlyé, Pascal E. Reiller. Contribution of capillary electrophoresis to an integrated vision of humic substances size and charge characterizations. Journal of Colloid and Interface Science, 2011, 368, pp.231-240. 10.1016/j.jcis.2011.11.046 . cea-00663002

\section{HAL Id: cea-00663002 \\ https://hal-cea.archives-ouvertes.fr/cea-00663002}

Submitted on 13 Sep 2019

HAL is a multi-disciplinary open access archive for the deposit and dissemination of scientific research documents, whether they are published or not. The documents may come from teaching and research institutions in France or abroad, or from public or private research centers.
L'archive ouverte pluridisciplinaire HAL, est destinée au dépôt et à la diffusion de documents scientifiques de niveau recherche, publiés ou non, émanant des établissements d'enseignement et de recherche français ou étrangers, des laboratoires publics ou privés.

\section{(ㅇ)(1) 80}

Distributed under a Creative Commons Attribution - NonCommercial - ShareAlikel 4.0 


\title{
Contribution of capillary electrophoresis to an integrated vision of humic substance size and charge characterization
}

\author{
Fanny d'Orlyé ${ }^{\dagger} \&$ Pascal E. Reiller*
}

Commissariat à l'Energie Atomique et aux énergies alternatives, CE Saclay,

CEA/DEN/DANS/DPC/SECR/LSRM, Bâtiment 391 PC 33, F-91191 Gif-sur-Yvette CEDEX, France.

* corresponding author. Tel. : +33169084312; fax : +33169085411.

E-mail address: pascal.reiller@cea.fr (P. E. Reiller)

$\dagger$ Present address: Laboratoire de Physicochimie des Electrolytes, Colloïdes et Sciences Analytiques UMR 7195, Chimie ParisTech, Ecole Nationale Supérieure de Chimie de Paris, 11 rue Pierre et Marie Curie - 75231 Paris Cedex 05, France.

Journal of Colloid and Interface Science 369 (1), 231-240

http://doi.org/10.1016/j.jcis.2011.11.046

\begin{abstract}
The physico chemical properties of three different humic substances (HS) are probed using capillary zone electrophoresis in alkaline carbonate buffers, $\mathrm{pH}$ 10. Special attention is drawn to the impact of the electrolyte ionic strength and counter-ion nature, chosen within the alkali-metal series, on HS electrophoretic mobility. Taylor-Aris dispersion analysis provides insights into the hydrodynamic radius $\left(\mathrm{R}_{\mathrm{H}}\right)$ distributions of HS. The smallest characterized entities are of nanometric dimensions, showing neither ionic strength- nor alkali-metal-induced aggregation. These results are compared to the entities evidenced in dynamic light scattering measurements, the size of which is two order of magnitude higher, $c a$. $100 \mathrm{~nm}$. The extended Onsager model provides a reasonable description of measured electrophoretic mobilities in the ionic strength range 1-50 mM, thus allowing estimation of limiting mobilities and ionic charge numbers for the different HS samples. An unexpected HS electrophoretic mobility increase (in absolute value) is observed in the order $\mathrm{Li}^{+}<\mathrm{Na}^{+}<\mathrm{K}^{+}<\mathrm{Cs}^{+}$and discussed either in terms of retarding forces or in terms of ion-ion interactions.
\end{abstract}




\section{ABBREVIATIONS}

Humic Substances (HS); Natural Organic Matter (NOM); Suwannee River Humic Acid (SRHA); Suwannee River Fulvic Acid (SRFA); Purified Aldrich Humic Acid (PAHA); Capillary Zone Electrophoresis (CZE); Background Electrolyte (BGE); Electroosmotic flow (EOF); Taylor dispersion analysis (TDA); Dynamic light scattering (DLS).

\section{INTRODUCTION}

The structure evolution of humic substances (HS), alkaline extracts of natural organic matter (NOM), with physical and chemical properties of solution has been a matter of debate for decades, even though more and more experimental evidence are pointing to an aggregation of rather small entities [1-3] in fractal organization [4-8]. The smallest objects evidenced up to now are of some nanometers in hydrodynamic radius [2,3]. Nevertheless, objects of some hundreds of nanometers have been commonly observed in dynamic light scattering [9-12]. Ionic strength has been identified as an influencing parameter on size and viscosity [12-14], acid-base properties [15,16], and affinity to metal ions [17,18]. But the extent of the ionic strength influence on size is not really clearly established. Some questions are still open: to which size scale does ionic strength actually affects the aggregate(s) size(s) of HS?; are the smallest objects affected, or does it only affect the already known larger aggregates seen in dynamic light scattering [12]?, and what is the actual influence of the alkaline cation?

The alkaline cations are weakly sorbed to HS [19], mostly non-specifically [20]. Influence of NOM on the cesium sorption onto minerals occurs mostly through the "blocking" of mineral sorption-sites by NOM more than through the direct Cs-NOM interaction [21]. Nevertheless, the influence of alkaline metals through ionic strength on acid-base properties induces an acidification $[15,16]$, which depends on the nature of the cation [19]. Some data are existing which compare $\mathrm{Na}^{+}$and $\mathrm{K}^{+}$[19], but to our knowledge no systematic study was performed throughout the alkaline series.

To provide a deeper insight into NOM-structure, a combination of complementary characterization techniques based on different physico chemical properties should be used, such as high performance size exclusion chromatography (HPSEC) [1], electrospray ionization mass spectrometry (ESI-MS) [22-25], atomic force microscopy (AFM) [2] or small angle neutron or X-ray scattering (SANS/SAXS) [5,6].

Over the last two decades, many authors have focused on the fingerprint characterization of HS using capillary-based electromigration techniques such as capillary zone electrophoresis (CZE) [26], capillary gel electrophoresis (CGE) [27], capillary isoelectric focusing (CIEF) [27,28] as well as micellar electrokinetic chromatography (MEKC) [27]. Special attention was paid to CZE as it combines the unique possibility to separate and detect NOM in aqueous solution within wide $p \mathrm{H}$ - and ionic strengthranges that allow mimicking environmental conditions. Characterizations were performed mainly using uncoated silica capillaries except in few cases where the authors aimed to minimize the electroosmotic flow (EOF) [29] or HS-sorption onto the capillary wall at low $p \mathrm{H}$ [30,31]. Among all separation electrolytes mentioned in the literature, the most frequently used are based on acetate [29,32], borate $[29,32,33]$, phosphate $[29,32-34]$ or phosphate-borate [33,35] buffer systems. More detailed information 
on the composition of the detected fractions were obtained using either diode array (DAD) or laserinduced fluorescence (LIF) detectors compared to that obtained using single-wavelength UV detection $[33,36]$. Commonly, NOM behave as anionic species in aqueous solutions and the injection of rather concentrated sample solutions (0.1-1 g.. $\left.\mathrm{L}^{-1}\right)$ produces typical fingerprints that are composed of a series of sharp peaks superimposed to a very broad hump sometimes followed by an asymmetrical peak on the higher mobility side. These electrophoretic patterns were interpreted as different HS-subfractions comigrating with a large supramolecular assembly consisting in an unresolved distribution of aggregate size and charge states. Nevertheless, only a mass-selective detector could allow differentiating the charge and mass distributions within the polydisperse humic samples. Thus, Schmitt-Kopplin and Kettrup [37] evaluated the use of CZE-ESI-MS for the characterization of Suwannee River NOM. They evidenced that the changes of the $\mathrm{m} / \mathrm{z}$ ratio distributions with mobility show a decrease of the $\mathrm{m} / \mathrm{z}$ ratio with increasing electrophoretic mobility in the humic hump at alkaline $p \mathrm{H}$; superimposed on this hump a lowmolecular-weight fraction migrates at lower mobility. Schmitt-Kopplin and Junkers [26] gave an indepth overview of the use of CZE in the characterization of NOM and looked at different pitfalls and artifacts that could come either from the instrumental setup or from separation buffer solution chemistry. In few words, they cautioned against the presence of a number of system peaks, which are inherent to the buffer or to different ionic strength distributions within the capillary (stacking effects). They also emphasized on artifacts caused by the potential interaction of buffer ions with HS samples, for instance in phosphate or borate buffers, which may improve signal reproducibility but become a problem when interpreting the data in relation to the size and charge distribution of native samples.

Because of problems in the interpretation of the complex electropherograms, CZE has been scarcely used for HS mobility measurements, and only few attempts have been made to evaluate the dependence of electrophoretic mobility on electrolyte composition ( $p \mathrm{H}$, ionic strength and chemical nature) as well as HS acid-base and complexation properties [34,38,39]. Schmitt-Kopplin and Junkers [26] related these problems to the choice of the separation electrolyte, especially reminding that borate ions compete with the same humic binding site as metals [40,41]. In this context, Norden and Dabek-Zlotorsynska [42] used capillary electrophoresis to study humic-metal interactions in borate-based buffer systems and ranked the investigated metal ions $\left(\mathrm{M}^{\mathrm{z}}\right)$ in order of decreasing complex stability: $\mathrm{Al}^{3+}>\mathrm{Hg}^{2+}>\mathrm{Cu}^{2+}>$ $\mathrm{Pb}^{2+}>\mathrm{Sr}^{2+}$, in agreement with the Irving-Williams series generally stated for HS-metal interactions [43]. This is also consistent with the work of Lubal et al. [44] who reported that humic acids bind strongly with heavy metal ions and the stability constant of HA-metal ion complexes were found to decrease in the order: $\mathrm{Cu}^{2+}>\mathrm{Ba}^{2+}>\mathrm{Pb}^{2+}>\mathrm{Cd}^{2+}>\mathrm{Ca}^{2+}$. Lately, there has been an effort to develop the applications of capillary electrophoresis hyphenated with inductively coupled plasma mass spectrometry (CE-ICPMS) to the study of HS-metal interactions, mainly lanthanides [45-53].

Beside electrokinetic measurements, the capillary electrophoresis instrument has proved to be well suited to perform Taylor dispersion analysis (TDA) as an alternative technique to determine the diffusion coefficients, $D$, of solute molecules [54]. It relies on the specific dispersion profile of a solute plug in a laminar Poiseuille flow, subjected to the combined effect of diffusion and convection. This method is attractive as it offers a possibility for a fast evaluation of $D$, based on the variance associated with the solute peak broadening or boundary sharpness, and thus estimation of the effective dimension of a given 
analyte in solution: the Stokes radius, $\mathrm{R}_{\mathrm{H}}$. Besides electrophoretic measurements, CE instrumentation has proved to be particularly well suited for performing TDA as it offers all the functions of injection, detection and data acquisition in a single automated apparatus. Recently characterized systems were as varied as phenylalanine, proteins, polymers, DNA fragments, colloidal particles or magnetic beads [5564].

The aims of the present work are i) to study the applicability of CZE for HS characterization in terms of size and charge distributions, which are the main properties that affect HS-reactivity in the environment, and ii) to estimate the influence of the electrolyte ionic strength $(I)$ and alkaline counterion nature $\left(\mathrm{M}^{+}=\mathrm{Li}^{+}, \mathrm{Na}^{+}, \mathrm{K}^{+}, \mathrm{Cs}^{+}\right)$on HS electrophoretic behavior.

\section{MATERIALS AND METHODS}

\subsection{Chemicals and reagents}

Standard $1 \mathrm{M}$ and $0.1 \mathrm{M} \mathrm{NaOH}$ solution Normadoses were purchased from VWR (Strasbourg, France). $\mathrm{Li}_{2} \mathrm{CO}_{3}$ and $\mathrm{K}_{2} \mathrm{CO}_{3}$ were obtained from Merck (Fontenay-sous-Bois, France). $\mathrm{Na}_{2} \mathrm{CO}_{3}$ and N,Ndimethylformamide were provided Fisher Scientific (Illkirch, France). $\mathrm{LiOH}, \mathrm{CsOH}\left(50\right.$ wt. \% in $\mathrm{H}_{2} \mathrm{O}$ ), standard 0.1 M KOH solution Fixanal, $\mathrm{Cs}_{2} \mathrm{CO}_{3}$ and humic acid were purchased from Sigma-Aldrich (Saint-Quentin Fallavier, France). $\mathrm{CO}_{2}$ in gas cylinder was provided by Messer (Puteaux, France). Suwannee River Humic Acid (SRHA) standard II and Suwannee River Fulvic Acid (SRFA) standard II were purchased from the International Humic Substances Society (IHSS, St. Paul, MN, USA) and used as received. Water used throughout was produced by a Barnstead Easypure II UV water purification system (Thermo Scientific, Dubuque, IA, USA).

\subsection{Separation electrolyte solutions}

The $0.1 \mathrm{M} \mathrm{LiOH}$ stock solution was prepared by dissolving $0.24 \mathrm{~g}$ of $\mathrm{LiOH}$ in $100 \mathrm{~mL}$ of deionized water. The $0.1 \mathrm{M} \mathrm{CsOH}$ stock solution was prepared by diluting $0.857 \mathrm{~mL}$ of the commercial $\mathrm{CsOH}$ (50 wt. \% in $\mathrm{H}_{2} \mathrm{O}$ ) solution in deionized water to a final volume of $100 \mathrm{~mL}$. All 5 and $0.1 \mathrm{mM}$ alkali hydroxide solutions were prepared from the corresponding $0.1 \mathrm{M}$ stock solution by applying successive dilutions in deionized water at 1:19 and 1:49, respectively. The $1 \mathrm{M}$ alkali carbonate stock solutions were prepared by dissolving $7.4 \mathrm{~g}, 10.6 \mathrm{~g}, 13.8 \mathrm{~g}$, and $32.6 \mathrm{~g}$ of $\mathrm{Li}_{2} \mathrm{CO}_{3}, \mathrm{Na}_{2} \mathrm{CO}_{3}, \mathrm{~K}_{2} \mathrm{CO}_{3}$, and $\mathrm{Cs}_{2} \mathrm{CO}_{3}$ in deionized water to a final volume of $100 \mathrm{~mL}$, respectively. All $0.1 \mathrm{M}$ alkali carbonate solutions were prepared from the corresponding $1 \mathrm{M}$ stock solution by applying a 1:9 dilution in deionized water. Carbonate buffer solutions of various ionic strengths (1 to $500 \mathrm{mM})$ were prepared by i.) dilution of predefined volumes $\mathrm{V}_{\mathrm{M}_{2} \mathrm{CO}_{3}}$, of alkali carbonate stock solutions $\left(\left[\mathrm{M}_{2} \mathrm{CO}_{3}\right]_{0}=1\right.$ or $\left.0.1 \mathrm{M}\right)$ in deionized water according to the desired $\mathrm{BGE}$ final volume $\mathrm{V}_{\mathrm{f}}$, and ii.) $\mathrm{CO}_{2}(\mathrm{~g})$ bubbling until $p \mathrm{H}$ stabilization at 10. The composition of the resulting separation electrolyte solutions is summarized in Table 1.

$\mathrm{N}, \mathrm{N}$-dimethylformamide was used as EOF marker at $0.01 \% \mathrm{v} / \mathrm{v}$ in buffer solution. 


\subsection{HS samples}

Aldrich Humic Acid was purified following the procedure described by Kim et al. [65]. Stock solutions of HS were prepared as follow: $10 \mathrm{mg}$ of each solid sample were weighed and solubilized in about $10 \mathrm{~g}$ of a $5 \mathrm{mM} \mathrm{MOH}$ solution by sonication for $10 \mathrm{~min}$. The resulting solution was constantly stirred during $24 \mathrm{~h}$ before $p \mathrm{H}$-measurement. Then, the $p \mathrm{H}$ of the stock solution was adjusted around 10 by addition of few microliters of a $0.1 \mathrm{M} \mathrm{MOH}$ solution until stabilization. HS sample solutions were obtained by a 1:1 dilution (final HS concentration $0.5 \mathrm{~g} . \mathrm{L}^{-1}$ ) in a buffer solution of identical $p \mathrm{H}$ and chemical nature but twice the ionic strength of the separation buffer. HS sample solutions were let stand overnight prior to analysis.

\subsection{CE apparatus and measurements}

A Beckman P/ACE MDQ system (Beckman Coulter, Inc., Fullerton, CA, USA) equipped with a diode array detector (DAD) was used for all CE experiments. Capillaries were prepared from bare silica tubing purchased from Polymicro Technologies (Phoenix, AZ, USA). Capillary dimensions were $50 \mu \mathrm{m}$ id $\times 60.6 \mathrm{~cm}$ (detection length $50 \mathrm{~cm}$ ). Prior to first use, bare fused-silica capillaries were activated by successive flushes: $1 \mathrm{M} \mathrm{NaOH}, 0.1 \mathrm{M} \mathrm{NaOH}$ and deionized water for 5 min each under 20 psi. Between each run, the capillary was rinsed by successive flushes: $0.1 \mathrm{M} \mathrm{MOH}$, deionized water and BGE for 1 min each under the aforementioned pressure. For the mobility measurements, successive hydrodynamic injections were performed in the following order: neutral marker (0.2 psi, $2 \mathrm{~s})$, BGE (0.2 psi, $2 \mathrm{~s}), \mathrm{HS}$ sample (0.2 psi, $5 \mathrm{~s}), \mathrm{BGE}(0.2 \mathrm{psi}, 2 \mathrm{~s})$. Separations were achieved by using the capillary short effective length $(10.6 \mathrm{~cm})$ and applying a $10 \mathrm{kV}$ voltage. For the TDA measurements, the inlet end of the capillary was transferred into the vial containing the HS sample and a mobilization pressure of 6 psi was applied for $3 \mathrm{~min}$ across the capillary previously filled with BGE, thus allowing recording concentration fronts (50 cm effective length to the detector). The temperature of the coolant liquid was set at $25{ }^{\circ} \mathrm{C}$. The detection wavelength for the EOF marker and HS were 200 and $254 \mathrm{~nm}$, respectively.

\subsection{Dynamic light scattering (DLS) apparatus and measurements}

DLS measurements were performed with a Nano ZS Zetasizer (Malvern Instrument, Worcestershire, UK) operating with a $\mathrm{He}-\mathrm{Ne}$ laser at a wavelength of $633 \mathrm{~nm}$ to independently determine the average diffusion coefficients and hydrodynamic radii of HS samples. The detection optics positioned at $173^{\circ}$ measures the back-scattered intensity. Measurement settings (duration, position, attenuator...) are automatically adjusted to accommodate the measurement quality requirements so that the count rates ranged from 138 to $212 \mathrm{kcps}$. HS solutions were analysed as prepared for the CE measurements. The samples were characterized in polystyrene disposable cuvettes (Sarstedt AG \& Co., Nümbrecht, Germany) and maintained at $25^{\circ} \mathrm{C}$ throughout the measurements.

\section{6. pH measurements}

The $p \mathrm{H}$ measurements were performed using a S20 SevenEasy $\mathrm{pH}$ Meter (Mettler Toledo, Columbus, $\mathrm{OH}, \mathrm{USA}$ ) equipped with a combined $\mathrm{pH}$ electrode (InLab Micro, Mettler Toledo). The pH probe was 
calibrated using high-precision $\mathrm{pH}$ buffers $(\mathrm{pH} 4.00,7.00$, and 10.00) obtained from Schott Geräte (Mainz, Germany).

\section{CALCULATION}

\subsection{Calculation of the HS electrophoretic mobility from the raw data}

The broadness and distortion of the HS electrophoretic profile (Figure 1) could make HS electrophoretic mobility determination difficult. Thus, we decided to calculate an average electrophoretic mobility from the time at $t_{\mathrm{HS}}^{\mathrm{c}}(\mathrm{s})$ the peak centroid (first normalized moment). The resulting apparent mobility $\mu_{\mathrm{HS}}^{\text {app }}\left(\mathrm{cm}^{2} \cdot \mathrm{V}^{-1} \cdot \mathrm{s}^{-1}\right)$ of a HS sample can be calculated according to the following expression,

$\mu_{\mathrm{HS}}^{\mathrm{app}}=\frac{\mathrm{L}_{\mathrm{d}} \mathrm{L}_{\mathrm{t}}}{\mathrm{t}_{\mathrm{HS}}^{\mathrm{V}} \mathrm{V}}$

where $\mathrm{L}_{\mathrm{d}}$ and $\mathrm{L}_{t}(\mathrm{~cm})$ are the effective length and total length of capillary relative to the detector, respectively, and $\mathrm{V}$ (Volt) the applied separation voltage. The conversion into effective mobility $\mu_{\mathrm{HS}}^{\text {eff }}$ $\left(\mathrm{cm}^{2} \cdot \mathrm{V}^{-1} \cdot \mathrm{s}^{-1}\right)$ involves the relation,

$\mu_{\mathrm{HS}}^{\text {eff }}=\mu_{\mathrm{HS}}^{\text {app }}-\mu_{\mathrm{eof}}=\frac{\mathrm{L}_{\mathrm{d}} \mathrm{L}_{\mathrm{t}}}{\mathrm{V}}\left(\frac{1}{\mathrm{t}_{\mathrm{HS}}^{\mathrm{c}}}-\frac{1}{\mathrm{t}_{\mathrm{eof}}}\right)$

in which

$\mu_{\text {eof }}=\frac{L_{d} L_{t}}{t_{\text {eof }} V}$

is the electroosmotic mobility of the buffer system employed, obtained from the migration time $t_{\text {eof }}(\mathrm{s})$ of a neutral molecule (N,N-dimethylformamide). 


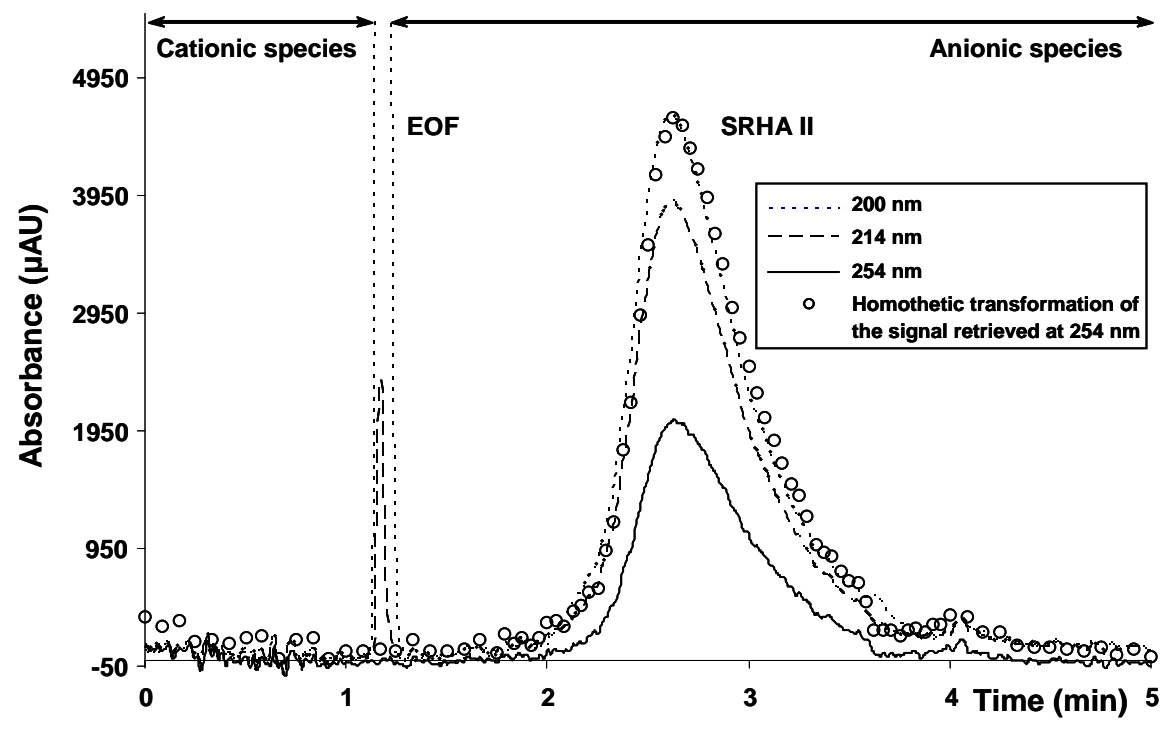

Figure 1: Electrophoretic profile at three different wavelengths of the IHSS reference SRHA II, 0.5 g.L $\mathrm{L}^{-1}$ in a $4 \mathrm{mM} \mathrm{Na} 2 \mathrm{CO}_{3} / \mathrm{CO}_{2}(\mathrm{~g})$ buffer $(I=10 \mathrm{mM}), p H$ 10. Experimental conditions: fusedsilica capillary, $50 \mu \mathrm{m}$ id $\times \mathbf{6 0 . 6} \mathrm{cm}$ (detection length $10.6 \mathrm{~cm}$ ); sample hydrodynamic injection 2 $\mathrm{nL}$; applied voltage $10 \mathrm{kV}$; temperature $25^{\circ} \mathrm{C}$; detection wavelengths 200,214 , and $254 \mathrm{~nm}$. The plot of the homothetic transformation of the signal retrieved at $254 \mathrm{~nm}$ represents one out of ten points.

\subsection{Calculation of the HS diffusion coefficient and hydrodynamic radius from the raw data}

The theoretical background of TDA is provided in more details elsewhere [58]. In this chapter, we will only remind the analytical solution (Eq. 4) of the convection-diffusion equation in the case of a front concentration profile,

$\frac{\overline{\mathrm{C}}}{\overline{\mathrm{C}_{0}}}=\frac{1}{2}+\frac{1}{2} \operatorname{erf}\left[\frac{\left(\mathrm{t}-\mathrm{t}_{\mathrm{R}}\right)}{\sigma \sqrt{2}}\right]$

where $\overline{\mathrm{C}}$ is the mean solute concentration across the cross section of the tube monitored as a function of time at a fixed position along the tube axis, $\overline{C_{0}}$ is the concentration of the front, $t_{R}$ is the mean residence time - the time it takes to the solute which moves with the mean velocity of the fluid, $u$, to reach the detector located at a distance $\mathrm{L}_{\mathrm{d}}$ from the inlet of the tube -, and $\sigma^{2}$ is the temporal variance of the elution profile related to the dispersion coefficient, $k$, by

$\sigma^{2}=2 \frac{k t_{R}}{u^{2}}$ 
Extending Taylor's theory, Aris [66] gave the following analytical expression for the dispersion coefficient $k$,

$k=D+\frac{\mathrm{R}_{\mathrm{C}}^{2} u^{2}}{48 D}$

where $\mathrm{R}_{\mathrm{C}}$ is the tube radius.

When $D<<\frac{\mathrm{R}_{\mathrm{C}}^{2} u^{2}}{48 D}$, the analyte diffusion coefficient can be determined combining Eqs 5 and 6:

$D=\frac{\mathrm{R}_{\mathrm{C}}^{2}}{24 \sigma^{2}} \mathrm{t}_{\mathrm{R}}$

Thus the diffusion coefficient can be directly determined from $\mathrm{t}_{\mathrm{R}}$ and $\sigma^{2}$ by solving $\mathrm{Eq} 7$ for $D$; $\mathrm{t}_{\mathrm{R}}$ and $\sigma^{2}$ being obtained by fitting Eq 4 to the UV detector signal at $254 \mathrm{~nm}$. Subsequently, HS hydrodynamic radius may be calculated from the Stokes-Einstein equation,

$D=\frac{\mathrm{k}_{\mathrm{B}} T}{6 \pi \eta \mathrm{R}_{\mathrm{H}}}$

where $\mathrm{k}_{\mathrm{B}} T$ is the thermal energy, $\eta$ is the fluid viscosity, and $\mathrm{R}_{\mathrm{H}}$ is the Stokes radius of the solute, respectively.

\section{RESULTS}

In this study, we were mainly interested in three HS samples: the Purified Aldrich Humic Acid (PAHA) and two samples from the IHSS originating from the Suwannee River (GA, USA): a humic (SRHA II) and a fulvic (SRFA II) acid.

\subsection{Electrophoretic mobility measurements}

Mobility measurements were performed in fused capillaries so that high magnitude cathodic EOF were generated in alkaline carbonate buffers, $p \mathrm{H} 10$. As for the HS samples, they are anionic in nature and thus migrated in a counter-electroosmotic mode. Nevertheless, under experimental conditions, their effective electrophoretic mobility, $\mu_{\mathrm{HS}}$, remained smaller (in absolute value) than the electroosmotic mobility, $\mu_{\text {eof }}$, so that they could be detected in the same run as the EOF marker. Alkali carbonate buffers, $p \mathrm{H}$ 10, were used because no interaction between the co-ion and our analytes were to be expected [26]. Moreover, as HS are known to undergo sorption on silica surfaces up to $p \mathrm{H} 6.5$ [67], separation electrolytes were chosen to induce a sufficiently high $p \mathrm{H}$ for the HS sorption onto the capillary wall to be negligible thanks to repulsive electrostatic forces. Under these conditions broad electrophoretic profiles (Figure 1) characteristic of heterogeneous samples presenting a wide distribution of size and charge states were observed. 
One of the questions arising from using separative techniques is the modification or fractionation of humic substances throughout the analytical run [1] or during a physico chemical process [25,68-71]. The implementation of a DAD allowed monitoring the electrophoretic profiles at different wavelengths (200, 214 and $254 \mathrm{~nm}$ ) specific of functional groups in the HS molecule. As evidenced by the perfect superimposition of the signal retrieved at $200 \mathrm{~nm}$ to the one retrieved at $254 \mathrm{~nm}$ after homothetic transformation (one out of ten points), the ratio between the different wavelengths was kept constant throughout the separation step (Figure 1). Hence, there is a strong indication that no structural modification of HS occurred during the separation by capillary electrophoresis $[25,68,70,71]$.

Electrophoretic mobility measurements were first performed in sodium carbonate buffers, $p \mathrm{H} \mathrm{10,} \mathrm{at}$ $I$ ranging from 5 to $250 \mathrm{mM}$. Under these conditions, we evidenced a significant decrease of the electrophoretic mobility of the 3 HS samples when increasing $I$ (Figure 2): i) from $-51.610^{-5} \mathrm{~cm}^{2} . \mathrm{V}^{-1} \cdot \mathrm{s}^{-1}$ $(\operatorname{RSD} 8.1 \%, \mathrm{n}=3)$ to $-32.610^{-5} \mathrm{~cm}^{2} . \mathrm{V}^{-1} \cdot \mathrm{s}^{-1}(\mathrm{RSD} 6.8 \%, \mathrm{n}=3)$, i.e. of $36.8 \%$ for the PAHA sample over an increasing $I$ from 5 to $250 \mathrm{mM}$; ii) from $-49.510^{-5} \mathrm{~cm}^{2} \cdot \mathrm{V}^{-1} \cdot \mathrm{s}^{-1}\left(\mathrm{RSD} 8.5 \%, \mathrm{n}=3\right.$ ) to $-28.710^{-5}$ $\mathrm{cm}^{2} \cdot \mathrm{V}^{-1} \cdot \mathrm{s}^{-1}$ (RSD $0.4 \%, \mathrm{n}=3$ ), i.e. of $42 \%$ for the SRHA II sample over an increasing $I$ from 5 to 250 $\mathrm{mM}$; iii) from $-49.610^{-5} \mathrm{~cm}^{2} . \mathrm{V}^{-1} \cdot \mathrm{s}^{-1}\left(\mathrm{RSD} 4.1 \%, \mathrm{n}=3\right.$ ) to $-31.810^{-5} \mathrm{~cm}^{2} \cdot \mathrm{V}^{-1} \cdot \mathrm{s}^{-1}$ (RSD $0.6 \%, \mathrm{n}=3$ ), i.e. of $35.9 \%$ for the SRFA II sample over an increasing $I$ from 5 to $200 \mathrm{mM}$.

If we now consider the influence of the BGE counter-ion nature, in alkali carbonate buffers, $p \mathrm{H} 10$, for various $\left[\mathrm{M}^{+}\right]$in the range $0.8-40 \mathrm{mM}$ (Figure 3), we observed a monotonous increase, in absolute value, in the electrophoretic mobility of all of the three $\mathrm{HS}$ samples going from $\mathrm{Li}^{+}$to $\mathrm{Cs}^{+}$within the alkali-metal series. This relative difference between HS effective mobilities measured in lithium and cesium carbonate buffers is enhanced with increasing metal ion concentrations ranging from 4.2-6.6\% at $8 \mathrm{mM}$ to over $10 \%$ at $40 \mathrm{mM}$, depending on the HS sample nature. Results obtained at metal ion concentrations lower than $4 \mathrm{mM}$ will be discarded in further modeling because of noticeably high measurement uncertainties (RSD values up to $12 \%, \mathrm{n}=4$ ) due to a poor buffering capacity of the separation electrolytes. 


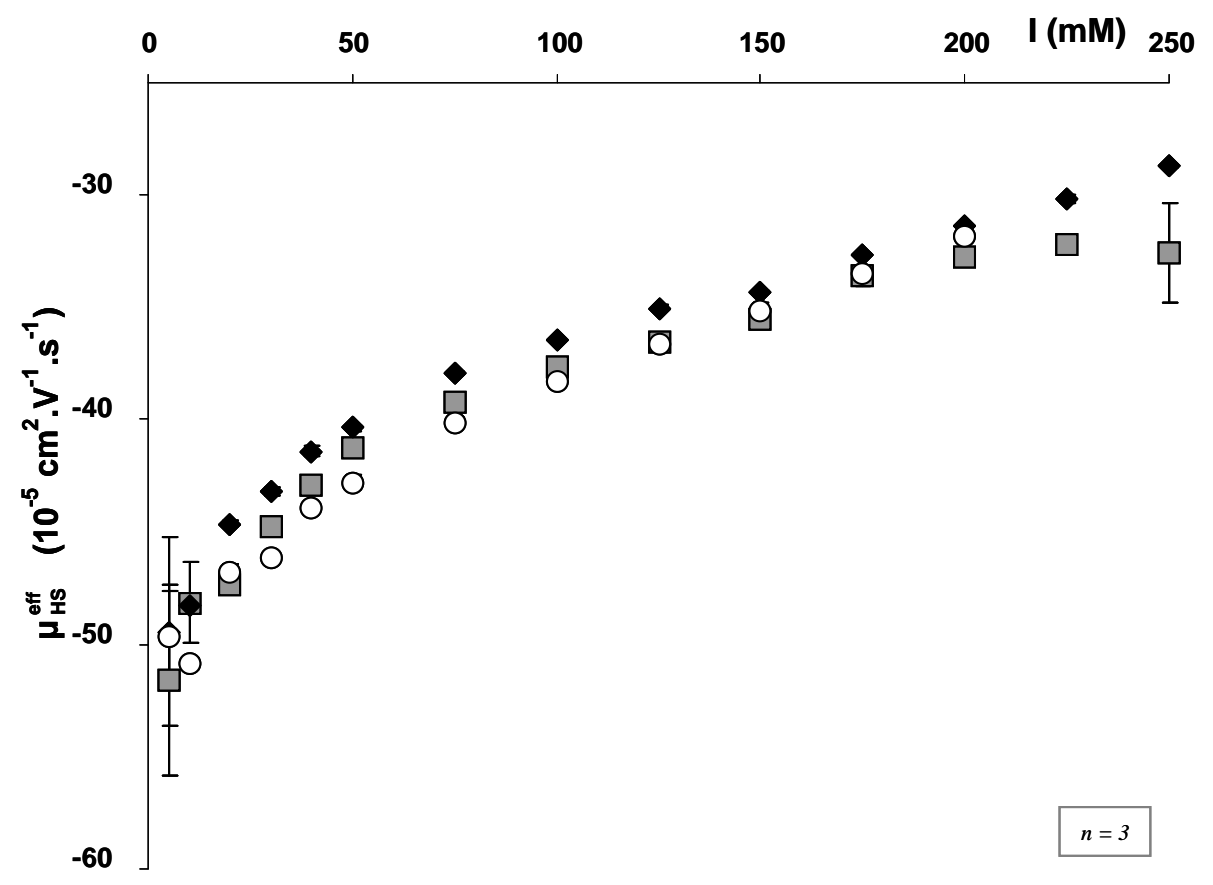

Figure 2: Electrophoretic mobilities of HS samples $\square$ PAHA; $\diamond$ SRHA II; $\bigcirc$ SRFA II) as a function of ionic strength $(5-250 \mathrm{mM})$ in sodium carbonate buffers, $p H$ 10. Experimental conditions: see Figure 1. 

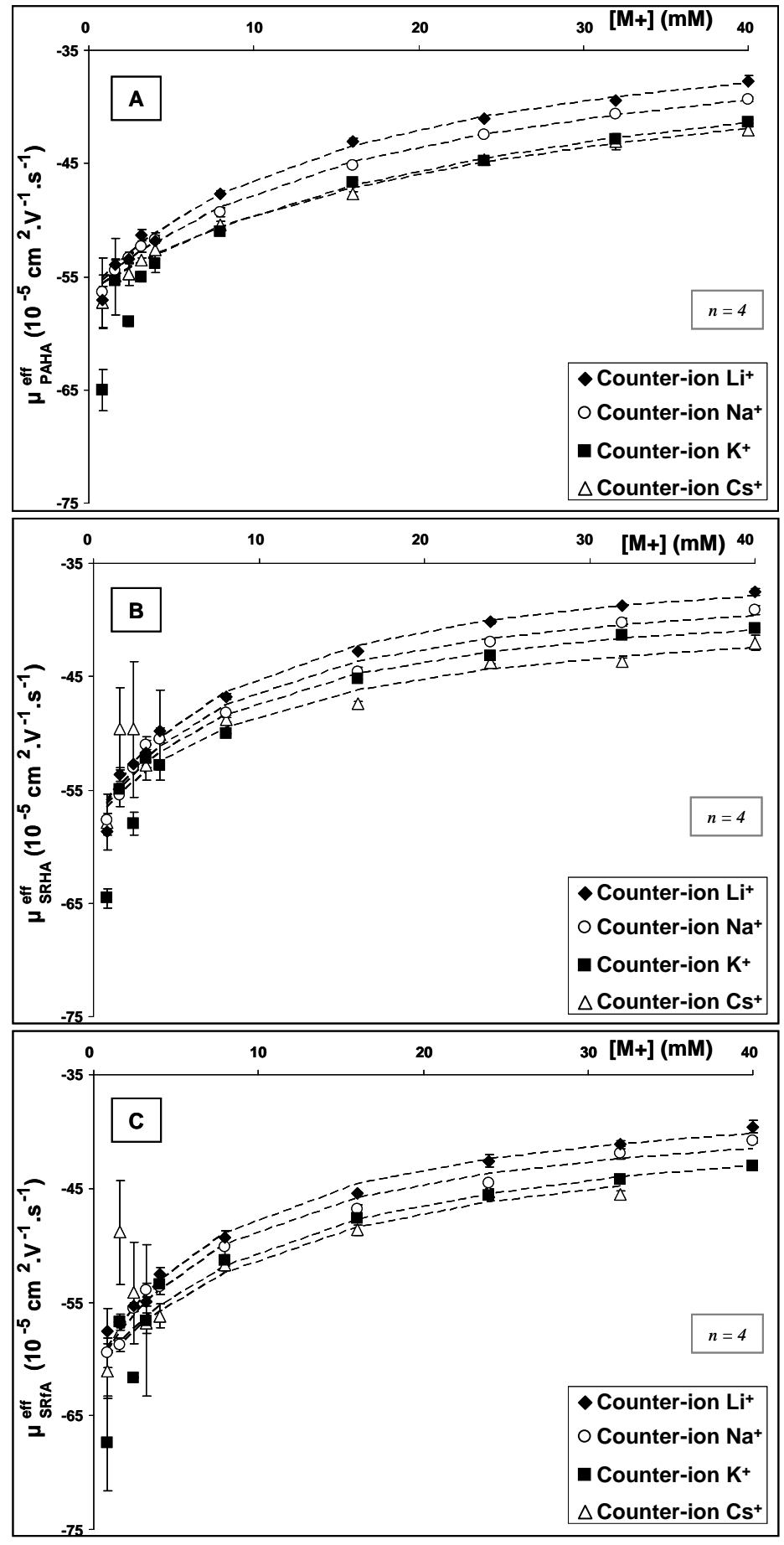

Figure 3: Electrophoretic mobilities of HS samples (3.A- PAHA; 3.B- SRHA II; 3.C-SRFA II) in carbonate buffers, $p \mathbf{H} 10$, as a function of the alkali-metal counter-ion $\left(\diamond \mathrm{Li}^{+}, \bigcirc \mathrm{Na}^{+}, \mathbf{\nabla} \mathbf{K}^{+}\right.$, $\left.\triangle \mathrm{Cs}^{+}\right)$concentration in the range 0.8-40 $\mathrm{mM}$. Dashed black lines are curves fitted to Eq. $11\left(\mathrm{r}^{2} \geq\right.$ 0.983). Experimental conditions: see Figure 1. 


\subsection{Hydrodynamic radii estimation}

\subsubsection{Taylor dispersion analysis (TDA)}

The coupling of CE with TDA was used to determine the average diffusion coefficient $(D)$ of the three HS. The non-linear least square fittings of Eq 4 for the front concentration profiles of mono-modal $D$ distributions were performed between 1.1 and $1.7 \mathrm{~min}$ with the Solver from Microsoft Excel. The uncertainties on the fitting parameters were calculated using the SolverAid Macro from de Levie [72]. Given the high number of experimental points in the profiles, the fittings of Eq 4 seemed rather satisfying giving determination coefficient $\left(\mathrm{r}^{2}\right)$ values higher than 0.999 . Nevertheless, the visual inspection of the concentration profiles characteristic of PAHA samples evidenced that Eq 4 did not entirely describe the experimental points (Figure 4.A, and insert), especially at the edges of the jump. The fitting was noticeably improved ( $\mathrm{r}^{2}$, but more interestingly the $\mathrm{F}$ parameter) by considering a bimodal $D$ distribution arising from a mixture of two different mono-modal $D$ distributions characterized by identical residence time $\left(t_{R}\right)$ but different temporal variances $\left(\sigma_{1}\right.$ and $\left.\sigma_{2}\right)$ and proportions $\left(x_{1}\right.$ and $\left.x_{2}=1-x_{1}\right)$, as can be seen from Figure 4.A on going from the dotted to the solid adjustment curve for the front concentration profile of PAHA solubilized in a $20 \mathrm{mM} \mathrm{Na} 2 \mathrm{CO}_{3} / \mathrm{CO}_{2}(\mathrm{~g})$ buffer $(I=50 \mathrm{mM}), \mathrm{pH} 10$. It is noteworthy that the correlation matrices did not evidence too high correlations between the parameters for each fitting of a PAHA front concentration profile, the maximum correlation being $\mathrm{r}\left(x_{2}, \sigma_{2}\right) \leq 0.93$.

In the case of the SRHA II (Figure 4.B) and SRFA II (Figure 4.C) samples, if a bimodal $D$ distribution did slightly improve the fittings, the adjustment parameters were getting significantly correlated; $\mathrm{r}\left(x_{1}\right.$, $\left.\sigma_{1}\right)$ and $\mathrm{r}\left(x_{2}, \sigma_{2}\right)$ over 0.98 for SRHA II, and over 0.99 for SRFA II, respectively. Moreover, it is to emphasize that the statistical parameters $(F)$ for the fitting of SRFA II front concentration profiles were not noticeably different when using a mono- or a bi-modal $D$ distribution. 

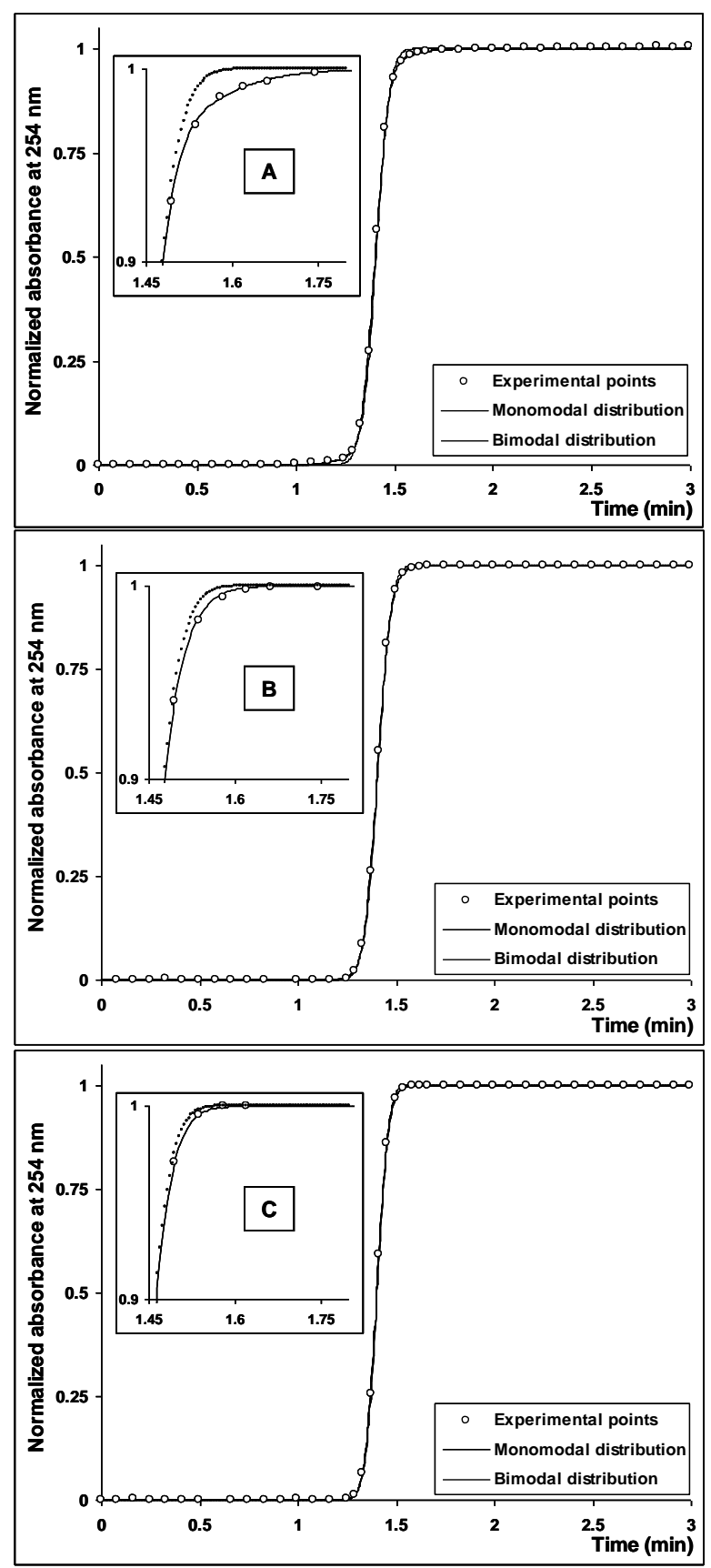

Figure 4: Experimental front concentration profiles (open circle, one tenth of the experimental points are represented for the sake of clarity) of HS samples (4.A- PAHA, 4.B- SRHA II, 4.CSRFA II) at $0.5 \mathrm{~g} / \mathrm{L}$ in a $20 \mathrm{mM} \mathrm{Na} \mathrm{CO}_{3} / \mathrm{CO}_{2}(\mathrm{~g})$ buffer $(I=50 \mathrm{mM})$, pH 10. Experimental conditions, see $\S 2.4$. Dotted and solid black lines are curves fitted to the analytical solution to the convection-diffusion equation (Eq. 4) assuming a mono-modal or bi-modal $D$ distribution, respectively.

From the $D$ mean values (derived from the bi-modal distribution) we estimated the equivalent $\mathrm{R}_{\mathrm{H}}$ for the all three HS samples using the Stokes-Einstein equation. This relies on the assumption that the objects characterized here can be considered as impermeable spheres [13]. The $R_{H}$ estimated in sodium 
carbonate buffers, $p \mathrm{H} \mathrm{10}$, are represented in a log-log scale as a function of the electrolyte ionic strength in the range 1 to $250 \mathrm{mM}$ on Figure 5. In this domain, no significant change in $\mathrm{R}_{\mathrm{H}}$ could be measured using the TDA that is to say that no ionic strength-induced aggregation could be evidenced for these objects in sodium carbonate buffers, $p \mathrm{H} 10$.

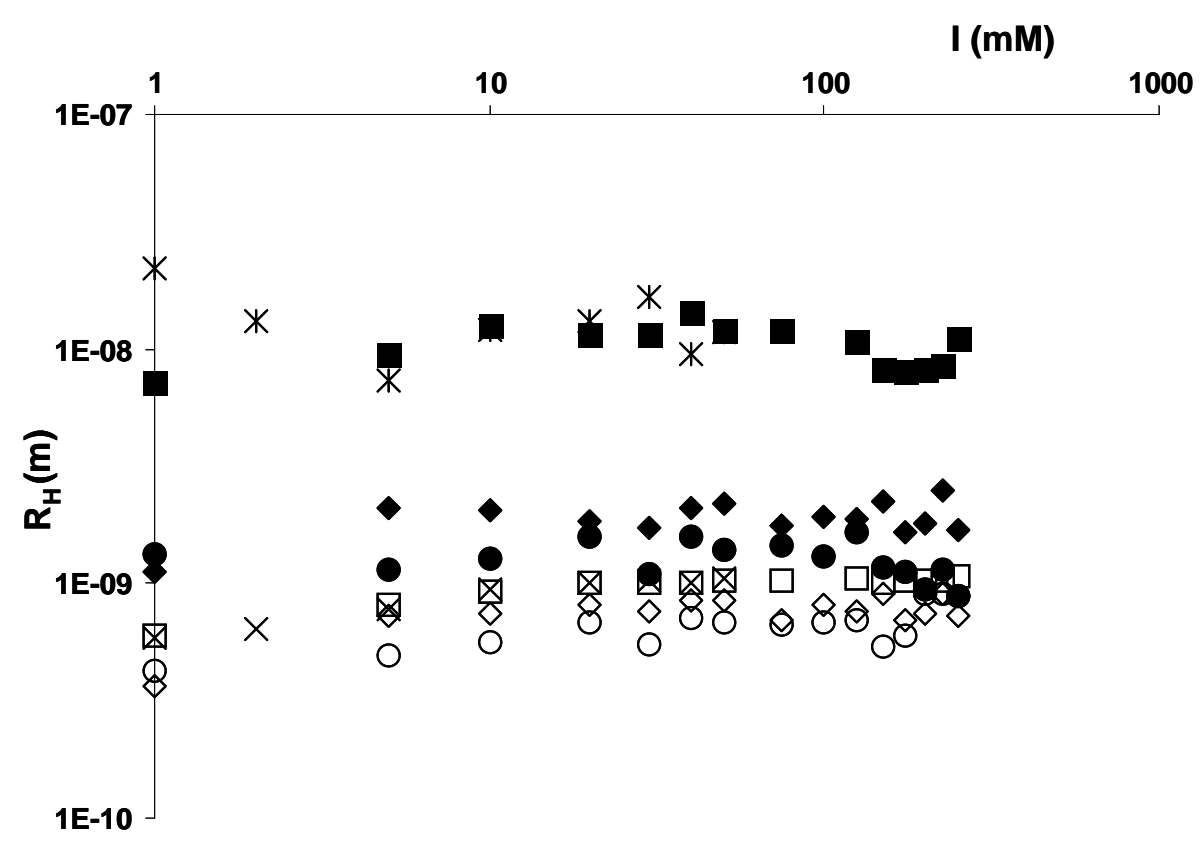

Figure 5: TDA-derived $R_{H}$ values and distributions for the HS samples as a function of ionic strength in (i) 1-250 mM sodium carbonate buffers, pH 10 ( $\square$ PAHA, $\diamond$ SRHA II, O SRFA II); (ii) 1-50 mM cesium carbonate buffers, pH 10 ( $\times$ PAHA). Full and open symbols represent the largest and smallest entities characterized in each bimodal distribution, respectively. Experimental conditions, see $§ 2.4$.

Concerning the estimated $\mathrm{R}_{\mathrm{H}}$ values and distributions reported in Table 2, one can highlight that PAHA is mainly composed $(89 \%)$ of entities of $0.97 \mathrm{~nm}$. This population coexists with a minor population (11\%) of 10 times larger objects, which may be supramolecular objects. As for the SRHA II and SRFA II samples, the fitting procedures gave quite comparable weight to the two modes with minor mean radii of 0.74 and $0.62 \mathrm{~nm}$, and major mean radii of 1.87 and 1.58, respectively. Assuming that the smallest detected entities represent the "hypothetical" single molecule, we found that the aggregation taking place could have resulted in the formation of di- or trimers. Nevertheless, we can discuss the choice of a bimodal size distribution as the two-estimated $R_{H}$ mean values are not different enough for the two modes to be resolved, given their intrinsic polydispersity. In this case, the consideration of a wide monomodal size distribution may have more physical meaning and the resulting estimated mean $\mathrm{R}_{\mathrm{H}}$ values are reported in Table 2 .

The same study was performed for an ionic strength ranging from 1 to $50 \mathrm{mM}$ in carbonate buffers,

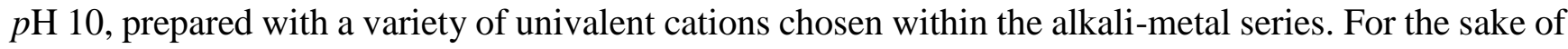
clarity, we only superimposed on Figure 5 the experimental points resulting from measurements 
performed on PAHA samples in cesium carbonate buffers. Thus, we clearly evidenced that the nature of the alkali-metal counter-ion did not significantly influence the value of the estimated $R_{H}$.

\subsection{2. $D L S$}

The z-average (intensity weighted average) hydrodynamic radius of HS samples was independently estimated by dynamic light scattering (DLS) in sodium carbonate buffers, $p \mathrm{H} 10$. The main limitation of DLS in relation to the present work is that, because the refractive index and basic geometry of our samples is unknown, DLS is not able to deal with their polydispersity in order to produce their size distribution profile. Despite the bias due to both polydispersity and shape, $\mathrm{z}$-average $\mathrm{R}_{\mathrm{H}}$ values can still be used as qualitative information on aggregative processes [73].

No satisfying measurements could be performed on SRFA II samples at a concentration of $0.5 \mathrm{~g} . \mathrm{L}^{-1}$. It is also worth noting that measurements performed on SRHA II samples of identical concentration (i) suffered of a noticeable lack of reproducibility $(4.5 \% \leq \mathrm{RSD} \leq 35.4 \%$ ), and (ii) did not meet data quality criteria for cumulant analysis. This may be attributed to the weak scattering properties of these two HS, as well as to their polydisperse and poorly cohesive nature comparing with PAHA, the measurement of which give rise to a far greater stability $(\mathrm{RSD} \leq 2.1 \%)$. The $\mathrm{z}$-average $\mathrm{R}_{\mathrm{H}}$ values estimated in sodium carbonate buffers, $p \mathrm{H} \mathrm{10}$, were about $109 \pm 4.2$ and $126 \pm 33 \mathrm{~nm}$ (weighted average and standard deviations) for the PAHA and SRHA II samples, respectively. As can be seen on Figure 6, there were no detectable dependence of the $\mathrm{z}$-average $\mathrm{R}_{\mathrm{H}}$ on the electrolyte ionic strength in the range 1 to $50 \mathrm{mM}$.

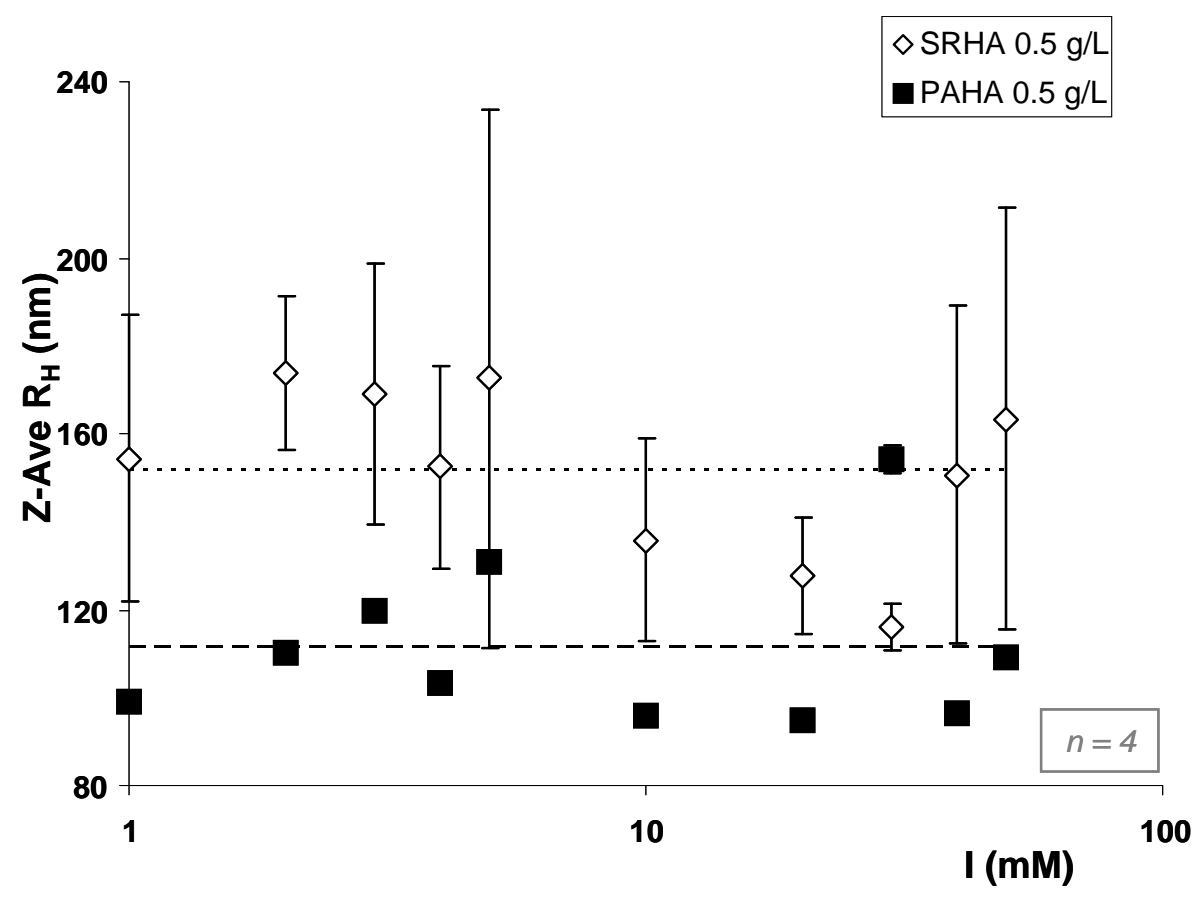

Figure 6: DLS-derived z-average $R_{H}$ values for the HS samples ( $\square$ PAHA, $\diamond$ SRHA II) as a function of ionic strength (1-50 mM) in sodium carbonate buffers, pH 10. Experimental conditions, see $§ 2.5$. 


\section{DISCUSSION}

\subsection{Comparison between $R_{H}$ values derived from TDA and DLS}

Although the z-average $\mathrm{R}_{\mathrm{H}}$ obtained in this study lie in the range of values $(60-500 \mathrm{~nm})$ previously reported in the literature for the DLS characterization of HS size [6,9-11], they are 2 orders of magnitude larger than the weight-average hydrodynamic radii obtained by TDA for a mass concentration-sensitive detector (UV). This contradiction is only apparent knowing the two techniques do not probe the same volume. Actually, the z-average value gives larger weight to the slowly diffusing entities. Thus in DLS, large-sized objects present in the sample will mask the presence of the low molecular weight compounds due to the $\mathrm{R}_{\mathrm{H}}{ }^{6}$ dependence of scattered light intensity on equivalent particle hydrodynamic radius. Therefore, in the two systems under comparison here (PAHA and SRHA II), it is consistent that 100 nm-sized objects, although a minority (less than 1\%o), could be evidenced using DLS but not by TDA.

This duality seems inherent to the techniques used for HS characterization. Besides TDA, nanometersized entities have already been proposed for different HS extracts in AFM [2] and flow field flow fractionation (FFFF) [3,74]. The analyses of surface tension experiments using the Gibbs equation also end up in nanometer-sized entities at the water-air interface [75,76]. However, small angle neutron (SANS) or X ray (SAXS) scattering of HS shows that fractal aggregates exist between $c a .1$ and $200 \mathrm{~nm}$ [4-7]. Hence, it seems that the particles observed in DLS and in TDA are different HS-entities. DLS, due to its $\mathrm{R}_{\mathrm{H}}^{6}$ dependence, apparently probes the larger entities, whereas TDA probes the smaller-sized entities.

Another complementary explanation may be that under DLS measurement conditions, HS samples are only submitted to their Brownian motion and heterogeneous single nanometric entities may selfassemble so that large-scale fractal supramolecular structures could be evidenced. Nevertheless, such structures only stabilized by weak forces may dissociate when set into motion under a Poiseuille flow, which can account for the shift in average size range observed in TDA. One may also note that size determination of HS in FFFF, which is also setting HS into motion, ends up in nanometer-sized entities $[3,74]$. The larger z-average $R_{H}$ values and temporal instability of measurements (four consecutive runs) resulting from the SRHA II sample characterization by DLS would then be consistent with a poorly cohesive nature compared to PAHA.

\subsection{Influence of the electrolyte ionic strength}

Varying the ionic strength of the alkali carbonate buffers, $p \mathrm{H} \mathrm{10,} \mathrm{we} \mathrm{did} \mathrm{not} \mathrm{observe} \mathrm{any} \mathrm{effect} \mathrm{on}$ $\mathrm{R}_{\mathrm{H}}$, which allow attributing the concomitant decrease in measured effective mobility to a charge screening effect. In an attempt to describe the mobility dependence of HS on the BGE ionic strength we first resorted to the models proposed by Wiersema et al. [77] and O'Brien and White [78] but we evidenced the limit in modelling the electrokinetics of humic particles when viewed as hard spheres. Actually, these models concern rigid colloidal particles with a homogeneous surface charge distribution, which is physically inappropriate in the case of HS. The present work, the only purpose of modelling HS as hard spheres was to estimate their equivalent hydrodynamic radius and by the same their ionic 
size parameter as a required input data for further analytic model when interpreting their electrophoretic mobility dependence on electrolyte ionic strength. Second, we considered the electrokinetic model for a diffuse soft particle, i.e. a spherical core/polymeric shell particle, taking into account the possibility of an inhomogeneous distribution of the hydrodynamically fixed and partially dissociated ionogenic groups within the polyelectrolyte layer, as proposed by Duval et al. [39]. Thus, the later authors succeeded in giving a quantitative interpretation of the electrophoretic mobilities of HS by numerical evaluation of the relevant electrostatic and transport equations. A key parameter in their model is the softness parameter, which characterizes the degree of flow penetration (permeability) to liquid flow of soft particles. The typical hydrodynamic penetration length found for humic particles is the order of magnitude of one third of their hydrodynamic radius, which in our case would range about $0.3 \mathrm{~nm}$, the order of magnitude of the molecular diameter of a water molecule or the hydrated radius of an alkalicounter ion. From this point of view, the relevance of the diffuse soft particle model seems questionable when applied to entities as small as those evidenced here, the size of which is nearly comparable to the one of the electrolyte counter-ions. Eventually, we used the extended Onsager model (Eq. 9) that may appear much too simplistic to explain the mobility dependence of HS on the BGE ionic strength, but has already proved to be well suited to describe the electrophoretic behavior of organic polyacids (aliphatic and aromatic carboxylic and sulfonic acids as well as phenols) of charge number ranging from -1 to -6 and size parameter values up to $0.73 \mathrm{~nm}[79,80]$ which is the order of magnitude of the equivalent hydrodynamic radius of the single nanometric entities evidenced here using TDA. Besides, the extended Onsager model is valid up to $I=100 \mathrm{mM}$, compatible with CE experimental conditions, and takes into account the ionic size of the analyte [79],

$\mu_{\mathrm{HS}}=\mu_{\mathrm{HS}}^{0}-\left(\mu_{\mathrm{HS}}^{0} \mathrm{~B}_{1} \mathrm{z}_{\mathrm{M}^{+}}\left|\mathrm{z}_{\mathrm{HS}}\right| \frac{q}{1+\sqrt{q}}+\left|\mathrm{z}_{\mathrm{HS}}\right| \mathrm{B}_{2}\right) \times \frac{\sqrt{I}}{1+\mathrm{B} a \sqrt{I}}$

where $\mu_{\mathrm{HS}}^{0}$ and $\mathrm{z}_{\mathrm{HS}}$ are the HS limiting mobility and charge number, $a$ is the ionic size parameter (shortest distance between the analyte and the counter-ion centers), $\mathrm{z}_{\mathrm{M}^{+}}$is the alkali metal cation charge number, $q$ is a parameter that depends on the charge numbers and limiting mobilities of the two ionic species, and $\mathrm{B}, \mathrm{B}_{1}$ and $\mathrm{B}_{2}$ are constants equal to $3.30 \times 10^{9} \mathrm{~m}^{-1} \cdot \mathrm{dm}^{1.5} \cdot \mathrm{mol}^{-0.5}, 0.79 \mathrm{dm}^{1.5} \cdot \mathrm{mol}^{-0.5}$ and $31.88 \times 10^{-9}$ $\mathrm{m}^{2} \cdot \mathrm{V}^{-1} \cdot \mathrm{s}^{-1} \cdot \mathrm{dm}^{1.5} \cdot \mathrm{mol}^{-0.5}$, respectively, when calculated for aqueous solutions at $25^{\circ} \mathrm{C}$.

The plot of measured HS mobility values versus the Debye-Hückel parameter $\sqrt{I} /(1+\mathrm{B} a \sqrt{I})$ is shown on Figure 7 for the three HS samples in carbonate buffers, $p \mathrm{H} 10$, prepared with a variety of univalent cations chosen within the alkali-metal series $\left(\mathrm{M}^{+}=\mathrm{Li}^{+}, \mathrm{Na}^{+}, \mathrm{K}^{+}, \mathrm{Cs}^{+}\right)$. They display a good linearity in the $I$-range from 1 to $50 \mathrm{mM}$. To do so, TDA derived average $\mathrm{R}_{\mathrm{H}}$ values of $1.32,1.20$ and $0.88 \mathrm{~nm}$ were assimilated to the ionic size parameter $a$ (Eq. 9) of the PAHA, SRHA II and SRFA II samples, respectively. Regression analysis of the measured HS mobility values (Figure 7, dashed black lines) to Eq. 9 allowed estimation of the three adjustment parameters $\mu_{\mathrm{HS}}^{0}$, ZHS and $q$. The estimated $\mu_{\mathrm{HS}}^{0}$ and ZHS values are reported in Table 3. As the parameters ZHS and $q$ are highly correlated, it does not seem reasonable to propose an estimate of their standard deviation. Nevertheless, we calculated the RSD of the slope of the linear regressions that ranged between 1.6 and $6.1 \%$. 
The estimated ionic charges $\mathrm{z}_{\mathrm{HS}}$ are of the same order of magnitude for the all three HS samples and range from 4.6 to 4.8. In order to validate these estimated values, and thus the use of the extended Onsager model to describe the electrophoretic behavior of HS fractions, we aimed to recalculate the total acidity of the HS under study, which can be experimentally measured and is already widely reported in the literature [81,82]. Nevertheless, this approach requires the knowledge of HS molecular weights, which raises another debate [83]. Considering the intrinsic heterogeneity of the HS samples as well as the bias inherent to each characterization technique, the number-averaged molecular weight of aquatic HA and FA fractions could be estimated ranging between 873 and 1630 g.mol ${ }^{-1}$, and 441 and 1360 g.mol ${ }^{1}$, respectively, the lowest values emanating from ESI-MS measurements and the highest from HPSEC ones [22-25,84-87]. The resulting estimates of HS total acidity, at $\mathrm{pH} 10$, range between 2.9-5.5, 2.85.3, and 3.4-10.4 meq. g $^{-1}$ for PAHA, SRHA II, and SRFA II samples, respectively, which are rather broad estimates because of the uncertainty on the molecular weight determination but encompass the values emanating from titration experiments [81,82]: about 4-4.5, 5-5.5 and 6.5-7 meq.g ${ }^{-1}$ for PAHA, SRHA II, and SRFA II samples, respectively. 

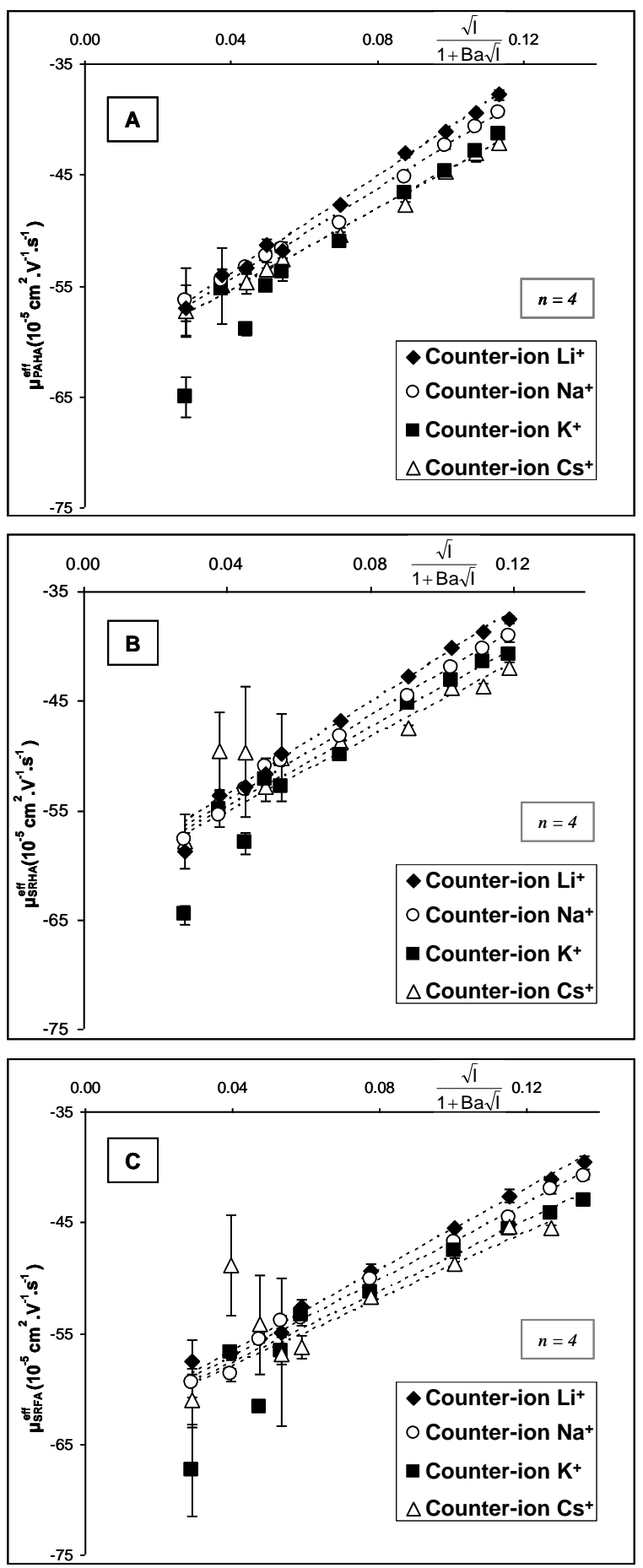

Figure 7: Electrophoretic mobilities of HS samples (7.A- PAHA, 7.B- SRHA II, 7.C- SRFA II) as a function of $\sqrt{\mathrm{I}} /(1+\mathrm{B} a \sqrt{\mathrm{I}})$ in carbonate buffers, $p \mathrm{H} 10$, prepared with a variety of univalent cations chosen within the alkali-metal series $\left(\diamond \mathrm{Li}^{+}, \bigcirc \mathrm{Na}^{+}, \mathbf{\square} \mathrm{K}^{+}, \triangle \mathrm{Cs}^{+}\right)$. Dashed black lines are curves fitted to Eq. 9 ( $\left.r^{2} \geq 0.972\right)$. Experimental conditions: see Figure 1 . 


\subsection{Influence of the electrolyte alkali counter-ion nature}

As shown on Figure 3, the choice of the counter-ion has a significant effect on the electrophoretic mobility of the HS: measured mobility increases in absolute value in the order $\mathrm{Li}^{+}<\mathrm{Na}^{+}<\mathrm{K}^{+}<\mathrm{Cs}^{+}$. Actually, one would expect a reversed order. Indeed, as the absolute ionic mobility (at infinite dilution) of these alkali-metal cations increases from $\mathrm{Li}^{+}$to $\mathrm{Cs}^{+}$, the cationic environment around the anionic $\mathrm{HS}$ would yield enhanced relaxation effect and, consequently, a diminished electrophoretic mobility of the HS [88].

Nevertheless, a second force exerted on the HS and caused by their ionic atmosphere is to be considered: the flow of solvent in the vicinity of HS resulting from the counter-ion migration in the opposite direction to that of the anionic analytes generates a retarding force known as the electrophoretic retardation. The ion micro-viscosity of common mono-atomic cations such as the alkali-metals was considered by Mauerhofer et al. [89]. Thus, ions with low charge density - in our case $\mathrm{K}^{+}$and $\mathrm{Cs}^{+}-$are described as "structure breakers", or chaotropes [90], as the structure of the water in their vicinity appears more disordered than in the bulk solvent, which explains their abnormally high ionic mobility. By comparison, ions with a high charge density - in our case $\mathrm{Li}^{+}$and $\mathrm{Na}^{+}$- are described as "structure makers", or kosmotropes [90], as they induce a gain of order for the water molecules in their vicinity. In this context, the friction force exerted on the HS by the solvent flow should be at its greatest magnitude when induced by the $\mathrm{Li}^{+}$migration comparing with the other alkali-metal cations. In the balance of forces to which are submitted the HS, if the electrophoretic retardation prevails on the relaxation effect, we should expect the HS electrophoretic mobility to increase in absolute value in the order $\mathrm{Li}^{+}<\mathrm{Na}^{+}<\mathrm{K}^{+}$ $<\mathrm{Cs}^{+}$, as observed experimentally.

As we already evidenced that the type of counter-ion did not influence the size parameter, we could also explain the observed increase in measured electrophoretic mobility by a decrease in ion association between HS and the BGE counter-ion on going from the $\mathrm{Li}^{+}$to the $\mathrm{Cs}^{+}$in the alkali-metal series. The greater impact of $\mathrm{Li}^{+}$on anionic analyte mobility was already observed in the literature for carboxylate and sulfonate [80,88] as well as for carbonate complexes of lanthanide(III) [91]. Since the Onsager model is based entirely on electrostatic theories, it cannot describe properly a system in which specific interactions such as ion association between analytes and BGE constituents take place. For the sake of simplicity, a 1:1 interaction model between an alkali-metal cation $\mathrm{M}^{+}$and the anionic analyte $\mathrm{HS}^{\mathrm{z}-}$ of effective charge $\mathrm{z}$ is applied here to extract interaction information from our series of electropherograms. The equilibrium and association constant are as follows.

$$
\mathrm{M}^{+}+\mathrm{HS}^{\mathrm{z}-} \rightleftarrows \mathrm{M}^{+} . \mathrm{HS}^{\mathrm{z}-} \quad K=\frac{\left[\mathrm{M}^{+} . \mathrm{HS}^{\mathrm{z}-}\right]}{\left[\mathrm{M}^{+}\right]\left[\mathrm{HS}^{\mathrm{z}-}\right]}
$$

Thus, the apparent electrophoretic mobility of the considered HS in the presence of ion association is given by, 
$\mu_{\mathrm{HS}^{2-}}^{\prime}=\frac{1}{1+K\left[\mathrm{M}^{+}\right]} \mu_{\mathrm{HS}^{2-}}+\frac{K\left[\mathrm{M}^{+}\right]}{1+K\left[\mathrm{M}^{+}\right]} \mu_{\mathrm{M} \cdot \mathrm{HS}^{(2-1)-}}$

where $\mu_{\mathrm{HS}^{2-}}$ and $\mu_{\mathrm{M} . \mathrm{HS}^{(z-1)-}}$ are the electrophoretic mobility of the unassociated and associated HS, respectively.

The electrophoretic mobilities of the three HS samples measured in carbonate buffers, $p \mathrm{H} 10$, is represented on Figure 3 as a function of the alkali-metal counter-ion $\left(\mathrm{Li}^{+}, \mathrm{Na}^{+}, \mathrm{K}^{+}, \mathrm{Cs}^{+}\right)$concentration in the range $0.8-40 \mathrm{mM}$. Non-linear least square regression analyses (Figure 3, dashed black lines) to Eq 11 allowed estimation of the three adjustment parameters $\mu_{\mathrm{HS}^{z}}, \mu_{\mathrm{M}_{\mathrm{HS}} \mathrm{S}^{--}}$and $K$. The estimated $\log _{10} K$ values are reported for the all three HS sample in Table 4. They range from 1.6 to 1.8 for PAHA and are slightly higher for SRHA II and SRFA II (between 1.9 and 2.1) probably because of their higher charge density. It is to emphasize here that the stability constants for alkali-metal organic complexes are scarce in the literature. Nevertheless, the ones tabulated by Martell and Smith [92] for carboxylates consistently show association slightly increasing from $\mathrm{Cs}^{+}$to $\mathrm{Li}^{+}$, with $\log _{10} K$ ranging from 0.8 to 0.3 for a citrate anion in a solution of $0.1 \mathrm{M}$ ionic strength at $25^{\circ} \mathrm{C}$. For the case of a real polyelectrolyte, the polyacrylic acid, Gregor and Frederick [93] also evidenced an increasing interaction from $\mathrm{K}^{+}$to $\mathrm{Li}^{+}$.

\section{CONCLUDING REMARKS}

In the end, CE appears as an efficient tool for the characterization of HS samples under environmental conditions. It allows estimating structural parameters such as size and charge as well as highlighting of weak but specific interactions with BGE. This technique adds another insight into HS nature and provides significant evidence to support the concept of HS as collections of diverse low-molecular mass entities. Nevertheless, this raises the problem inherent to the technique used for HS characterization. Thus, one should remain critical on measurement scaling and measurement conditions that may be denaturing to the analyte.

An influence of the electrolyte ionic strength on the HS electrophoretic mobility was evidenced. The extent of decreasing HS mobility when increasing electrolyte ionic strength was well described by the extended Onsager model, which accounts for the ionic size parameter and allows estimation of the HS ionic charge in the ZHS range from 4.6 to 4.8. Problem arising from the estimation of the distance of closest approach between ion and counter-ion for these $a$ priori asymmetric analytes was bypassed using TDA for the estimation of HS equivalent hydrodynamic radii, which ranged between 0.88 and $1.32 \mathrm{~nm}$.

An influence of the alkali-metal cation nature on the HS electrophoretic mobility was evidenced. The greater decrease in HS electrophoretic mobility observed in the presence of lithium was unexpected but may be explained by an increasing ion micro-viscosity on going from $\mathrm{Cs}^{+}$to $\mathrm{Li}^{+}$or may indicate weak specific ion-ion interactions ( $\log _{10} K$ about 2$)$. 


\section{ACKNOWLEDGMENT}

Dr. Jean Aupiais (CEA/DAM/DASE) is acknowledged for fruitful conversations. This work was financed through the RBPCH program of the RSTB domain of CEA.

\section{REFERENCES}

[1] A. Piccolo, Soil Sci. 166 (2001) 810.

[2] M. Baalousha, J.R. Lead, Environ. Sci. Technol. 41 (2007) 1111.

[3] M. Bouby, T.N. Manh, H. Geckeis, F. Scherbaum, J.I. Kim, Radiochim. Acta 90 (2002) 727.

[4] R. Österberg, L. Szajdak, K. Mortensen, Environ. Int. 20 (1994) 77.

[5] R. Österberg, K. Mortensen, A. Ikai, Naturwissenschaften 82 (1995) 137.

[6] J.A. Rice, E. Tombácz, K. Malekani, Geoderma 88 (1999) 251.

[7] M.S. Diallo, C.J. Glinka, W.A. Goddard, J.H. Johnson, J. Nanopart. Res. 7 (2005) 435.

[8] P.S. Redwood, J.R. Lead, R.M. Harrison, I.P. Jones, S. Stoll, Environ. Sci. Technol. 39 (2005) 1962.

[9] M.S. Caceci, A. Billon, Org. Geochem. 15 (1990) 335.

[10] J.P. Pinheiro, A.M. Mota, J.M.R. d'Oliveira, J.M.G. Martinho, Anal. Chim. Acta 329 (1996) 15.

[11] T.J. Manning, D.M. Bennett, Sci. Total Environ. 257 (2000) 171.

[12] E. Tombácz, J.A. Rice, S.Z. Ren, ACH-Models Chem. 134 (1997) 877.

[13] M.J. Avena, L.K. Koopal, W.H. van Riemsdijk, J. Colloid Interface Sci. 217 (1999) 37.

[14] F. Rey, M.A. Ferreira, P. Facal, A. Machado, Can. J. Chem.-Rev. Can. Chim. 74 (1996) 295.

[15] D.S. Gamble, Can. J. Chem.-Rev. Can. Chim. 48 (1970) 2662.

[16] M.F. Benedetti, W.H. van Riemsdijk, L.K. Koopal, Environ. Sci. Technol. 30 (1996) 1805.

[17] K.R. Czerwinski, J.I. Kim, D.S. Rhee, G. Buckau, Radiochim. Acta 72 (1996) 179.

[18] G. Szabó, J. Guczi, P.E. Reiller, T. Miyajima, R.A. Bulman, Radiochim. Acta 98 (2010) 13.

[19] D.S. Gamble, Can. J. Chem.-Rev. Can. Chim. 51 (1973) 3217.

[20] S. Lofts, E.W. Tipping, A.L. Sanchez, B.A. Dodd, J. Environ. Rad. 61 (2002) 133.

[21] S. Staunton, C. Dumat, A. Zsolnay, J. Environ. Rad. 58 (2002) 163.

[22] G. Plancque, B. Amekraz, V. Moulin, P. Toulhoat, C. Moulin, Rapid Comm. Mass Spectrom. 15 (2001) 827

[23] V. Moulin, P. Reiller, B. Amekraz, C. Moulin, Rapid Comm. Mass Spectrom. 15 (2001) 2488.

[24] A. Piccolo, M. Spiteller, Anal. Bioanal. Chem. 377 (2003) 1047.
[25] P. Reiller, B. Amekraz, C. Moulin, Environ. Sci. Technol. 40 (2006) 2235.

[26] P. Schmitt-Kopplin, J. Junkers, J. Chromatogr. A 998 (2003) 1.

[27] R. Dunkelog, H.H. Ruttinger, K. Peisker, J. Chromatogr. A 777 (1997) 355.

[28] P. Schmitt, A.W. Garrison, D. Freitag, A. Kettrup, Water Res. 31 (1997) 2037.

[29] C. Ciavatta, M. Govi, C. Gessa, J. High Resolut. Chromatogr. 20 (1997) 67.

[30] D. Fetsch, M. Fetsch, E.M. Pena Mendéz, J. Havel, Electrophoresis 19 (1998) 2465.

[31] D. Fetsch, J. Havel, J. Chromatogr. A 802 (1998) 189.

[32] A.W. Garrison, P. Schmitt, A. Kettrup, Water Res. 29 (1995) 2149.

[33] E. Parlanti, B. Morin, L. Vacher, Org. Geochem. 33 (2002) 221.

[34] N.G. Vanifatova, A.G. Zavarzina, B.Y. Spivakov, J. Chromatogr. A 1183 (2008) 186.

[35] S. Pompe, K.H. Heise, H. Nitsche, J. Chromatogr. A 723 (1996) 215.

[36] M. Norden, E. Dabek-Zlotorzynska, Electrophoresis 18 (1997) 292.

[37] P. Schmitt-Kopplin, A. Kettrup, Electrophoresis 24 (2003) 3057.

[38] M. Hosse, K.J. Wilkinson, Environ. Sci. Technol. 35 (2001) 4301

[39] J.F.L. Duval, K.J. Wilkinson, H.P. van Leeuwen, J. Buffle, Environ. Sci. Technol. 39 (2005) 6435.

[40] P. Schmitt-Kopplin, N. Hertkorn, A.W. Garrison, D. Freitag, A. Kettrup, Anal. Chem. 70 (1998) 3798.

[41] P. Schmitt-Kopplin, A.W. Garrison, E.M. Perdue, D. Freitag, A. Kettrup, J. Chromatogr. A 807 (1998) 101

[42] M. Norden, E. Dabek-Zlotorzynska, J. Chromatogr. A 739 (1996) 421.

[43] H. Kerndorff, M. Schnitzer, Geochim. Cosmochim. Acta 44 (1980) 1701.

[44] P. Lubal, D. Siroky, D. Fetsch, J. Havel, Talanta 47 (1998) 401.

[45] R. Kautenburger, K. Nowotka, H.P. Beck, Anal. Bioanal. Chem. 384 (2006) 1416.

[46] J.C. Stern, J.E. Sonke, V.J.M. Salters, Chem. Geol. 246 (2007) 170.

[47] R. Kautenburger, J. Anal. At. Spectrom. 24 (2009) 934

[48] R. Kautenburger, H.P. Beck, J. Chromatogr. A 1159 (2007) 75. 
[49] J.E. Sonke, D.J. Furbish, V.J.M. Salters, J. Chromatogr. A 1015 (2003) 205.

[50] J.E. Sonke, V.J.M. Salters, J. Anal. At. Spectrom. 19 (2004) 235.

[51] J.E. Sonke, V.J.M. Salters, Analyst 129 (2004) 731.

[52] J.E. Sonke, V.J.M. Salters, Geochim. Cosmochim. Acta 70 (2006) 1495.

[53] X.B. Yin, Y. Li, X.P. Yan, Trac-Trends Anal. Chem. 27 (2008) 554.

[54] G. Taylor, Proc. R. Soc. London, Ser. A 219 (1953) 186.

[55] J. Ostergaard, H. Jensen, Anal. Chem. 81 (2009) 8644.

[56] J. Deschamps, S.G. Dutremez, B. Boury, H. Cottet, Macromolecules 42 (2009) 2679.

[57] T. Le Saux, H. Cottet, Anal. Chem. 80 (2008) 1829.

[58] F. d'Orlyé, A. Varenne, P. Gareil, J. Chromatogr. A 1204 (2008) 226.

[59] H. Cottet, J.P. Biron, L. Cipelletti, R. Matmour, M. Martin, Anal. Chem. 82 (2010) 1793.

[60] H. Cottet, M. Martin, A. Papillaud, E. Souaid, H. Collet, A. Commeyras, Biomacromolecules 8 (2007) 3235.

[61] H. Cottet, J.P. Biron, M. Martin, Anal. Chem. 79 (2007) 9066.

[62] U. Sharma, N.J. Gleason, J.D. Carbeck, Anal. Chem. 77 (2005) 806.

[63] B.M. Belongia, J.C. Baygents, J. Colloid Interface Sci. 195 (1997) 19.

[64] M.S. Bello, R. Rezzonico, P.G. Righetti, Science 266 (1994) 773.

[65] J.I. Kim, G. Buckau, G.H. Li, H. Duschner, N. Psarros, Fresenius J. Anal. Chem. 338 (1990) 245

[66] R. Aris, Proc. R. Soc. London, Ser. A 235 (1956) 67.

[67] P. Reiller, V. Moulin, F. Casanova, C. Dautel, Radiochim. Acta 91 (2003) 513.

[68] G.V. Korshin, C.-W. Li, M.M. Benjamin, Water Res. 31 (1997) 1787.

[69] J. Hur, M.A. Schlautman, J. Colloid Interface Sci. 264 (2003) 313.

[70] F. Claret, T. Schäfer, J. Brevet, P.E. Reiller, Environ. Sci. Technol. 42 (2008) 8809.

[71] N. Janot, P.E. Reiller, G.V. Korshin, M.F. Benedetti, Environ. Sci. Technol. 44 (2010) 6782.

[72] R. de Levie, Advanced Excel for Scientific Data Analysis, Oxford University Press, 2005.

[73] S. Batchelli, F.L.L. Muller, M. Baalousha, J.R. Lead, Marine Chem. 113 (2009) 227.
[74] M. Bouby, H. Geckeis, J. Lützenkirchen, S. Mihai, T. Schäfer, Geochim. Cosmochim. Acta 75 (2011) 3866.

[75] M. Tschapek, C. Wasowski, Geochim. Cosmochim. Acta 40 (1976) 1343.

[76] T.F. Guetzloff, J.A. Rice, Sci. Total Environ. 152 (1994) 31.

[77] P.H. Wiersema, A.L. Loeb, J.T. Overbeek, J. Colloid Interface Sci. 22 (1966) 78.

[78] R.W. O’Brien, L.R. White, J. Chem. Soc., Faraday Trans. II 74 (1978) 1607.

[79] D.A. Koval, V. Kasicka, I. Zuskova, Electrophoresis 26 (2005) 3221.

[80] D.M. Li, S.L. Fu, C.A. Lucy, Anal. Chem. 71 (1999) 687.

[81] J.D. Ritchie, E.M. Perdue, Geochim. Cosmochim. Acta 67 (2003) 85.

[82] C.J. Milne, D.G. Kinniburgh, E. Tipping, Environ. Sci. Technol. 35 (2001) 2049.

[83] P. MacCarthy, Soil Sci. 166 (2001) 738.

[84] G.R. Aiken, R.L. Malcolm, Geochim. Cosmochim. Acta 51 (1987) 2177.

[85] Y.-P. Chin, G. Aiken, E. O’Loughlin, Environ. Sci. Technol. 28 (1994) 1853.

[86] E.M. Thurman, R.L. Wershaw, M. R.L., D.J. Pinckney, Org. Geochem. 4 (1982) 27.

[87] M. Wolf, W. Szymczak, V. Chanel, G. Buckau, in G. Buckau (Editor), Humic Substances in Performance Assessment of Nuclear Waste Disposal: Actinide and Iodine Migration in the Far-Field. Second Technical Progress Report, Report FZKA 6969, http://bibliothek.fzk.de/zb/berichte/FZKA6969.pd f, Forschungszentrum Karlsruhe - Institut für Nukleare Entsorgung, Karlsruhe, Germany, 2004, p. 95.

[88] M.W.F. Nielen, J. Chromatogr. 542 (1991) 173.

[89] E. Mauerhofer, K. Zhernosekov, F. Rosch, Radiochim. Acta 91 (2003) 473.

[90] Y. Marcus, Ion Solvation, Wiley, Chichester, UK, 1985.

[91] V. Philippini, T. Vercouter, J. Aupiais, S. Topin, C. Ambard, A. Chausse, P. Vitorge, Electrophoresis 29 (2008) 2041.

[92] A.F. Martell, R.M. Smith, Critical Stability Constants, Plenum Press, New York, NY, USA, 1977.

[93] H.P. Gregor, M. Frederick, Journal of Polymer Science 23 (1957) 451. 